\title{
ANALISIS PENGARUH KEPUTUSAN MEMBELI RUMAH TINGGAL (Studi Empiris Masyarakat Kota Surakarta)
}

\author{
Dibyo Iskandar 1) Tri Nurdyastuti ${ }^{2}$ ) \\ STIE Adi Unggul Bhirawa Surakarta \\ tri.nurdyastuti@stie-aub.ac.id 1)
}

\begin{abstract}
ABSTRAK
Penelitian ini bertujuan untuk mengetahui sejauh mana peran lokasi, demografi dan sarana prasarana terhadap keputusan membeli rumah tinggal. Metode penelitian yang digunakan adalah survei. Alat pengumpulan data yang digunakan adalah kuesioner, sampel yang digunakan dalam penelitian ini berjumlah 100 responden dengan menggunakan teknik sampling accidental sampling. Analisis data yang dilakukan dengan menggunakan uji kualitas da yang terdiri dari uji validitas dan uji reliabilitas, uji Asumsi Klasik dan uji regresi linier. Hasil dari penelitian menunjukkan bahwa lokasi, demografi dan sarana prasarana berpengaruh positif dan signifikan terhadap keputusan membeli rumah tinggal bagi masyarakat di Kota Surakarta. Hasil uji determinasi diketahui bahwa pengaruh yang diberikan oleh variabel lokasi, demografi dan sarana prasarana mampu menjelaskan keputusan membeli rumah tinggal sebesar $85,7 \%$ sedangkan sisanya $14,3 \%$ dipengaruhi oleh variabel lain yang tidak termasuk dalam penelitian ini.
\end{abstract}

Kata kunci: lokasi, demografi, sarana prasarana, keputusan membeli.

This study aims to determine the extent of the role of location, demography and infrastructure facilities on the decision to buy a home. The research method used is a survey. The data collection tool used is a questionnaire, the sample used in this study amounted to 100 respondents using accidental sampling sampling technique. Data analysis was carried out by using a quality test consisting of validity and reliability tests, Classical Assumption tests and linear regression tests. The results of the study show that the location, demography and infrastructure have a positive and significant effect on the decision to buy housing for the people in Surakarta City. The results of the determination test are known that the influence given by location variables, demographics and infrastructure is able to explain the decision to buy a home by $85.7 \%$ while the remaining $14.3 \%$ is influenced by other variables not included in this study.

Keywords: location, demographics, infrastructure, buying decisions.

\section{PENDAHULUAN}

Memiliki rumah adalah salah satu kebutuhan pokok karena rumah adalah tempat untuk berlindung. Setiap orang berusaha untuk dapat membeli rumah baik secara kontan maupun secara kredit itu tergantung dengan kemampuan masingmasing orang untuk membeli rumah. Banyak pilihan yang dapat dijadikan pertimbangan seseorang untuk membeli rumah. Beberapa orang ada yang tinggal di kawasan perkampungan dan ada yang memilih tinggal di kawasan perumahan. Hal itu tergantung dari masing- masing pihak untuk menilai tempat yang mereka nilai nyaman untuk bertempat tinggal. Sebagai kota terbesar kedua di Jawa Tengah, Solo atau Surakarta dengan basis ekonomi industri tekstil, perdagangan dan pariwisata, layak menjadi incaran investasi properti. Bahkan dengan adanya kampus perguruan tinggi negeri, serta sekitar 22 perguruan tinggi swasta, kota itu menjadi salah satu tujuan pendidikan lulusan SMA di Indonesia.

Kota Surakarta dengan luas wilayah 44,04 $\mathrm{km}^{2}$ memiliki jumlah penduduk sebanyak 570.876 jiwa yang tersebar ke 5 wilayah kecamatan. Angka kepadatan penduduk Kota Surakarta adalah 12.963 artinya setiap km2 dihuni oleh 12.693 jiwa. Jika dilihat dari persebaran penduduk di setiap kecamatan, Kecamatan Pasar Kliwon merupakan kecamatan yang paling padat di wilayah Kota Surakarta dengan kepadatan mencapai $17.984 \mathrm{jiwa} / \mathrm{km} 2$. Adapun kecamatan yang memiliki kepadatan terendah adalah Kecamatan Jebres $11.623 \mathrm{jiwa} / \mathrm{km} 2$. Dari data tersebut dapat diketahui bahwa penduduk Kota Surakarta sangat padat sehingga mendorong munculnya perumahan-perumahan baru untuk mencukupi permintaan perumahan yang semakin meningkat dengan pertambahan penduduk yang semakin meningkat. 
Setiap manusia memiliki kebutuhan dasar yaitu sandang, pangan dan papan (rumah). Rumah atau tempat tinggal merupakan salah satu kebutuhan dasar yang diperlukan oleh manusia tidak hanya sebagai tempat tinggal, tetapi juga tempat untuk berlindung dari faktor eksternal (khususnya faktor alam seperti angin, hujan, sinar matahari, temperatur). Rumah pada umumnya terdapat penutup atap dan berteduh terhadap cuaca dan bertahan dari gangguan-gangguan lain, selain itu rumah juga tempat untuk berinteraksi dan bersosialisasi dalam komunitasnya serta sebagai tempat untuk mengaktualisasikan dirinya dalam masyarakat.

Banyak faktor yang mempengaruhi masyarakat memilih rumah tinggal, hal ini berkaitan dengan perilaku dari masyarakat/konsumen. Menurut Perner (2008) dalam (Mansoor \& Jalal, 2011, p. 105) secara umum perilaku konsumen adalah studi mengenai proses-proses dimana individu atau kelompok membuat pilihan pembelian konsumen dalam upaya memenuhi kebutuhan. Perilaku pembelian itu dapat bervariasi tergantung pada faktor internal seperti pendapatan, demografi, sosial dan budaya, serta faktor eksternal seperti lingkungan sekitar konsumen.

Menurut Porter (1974) dalam (Shah, et al., 2012, p. 107) bahwa minat untuk melakukan pembelian adalah jenis keputusan dalam mempelajari mengapa pelanggan membeli suatu merek secara khusus. Rangsangan pemasaran terdiri dari 4Ps (product, price, place, promotion), selain itu terdapat rangsangan lain yang bertindak sebagai kekuatan utama dalam lingkungan pembeli : economic technological, political, dan cultural.

Menurut Gilaninia (2010) dalam (Jeddi, Atefi, Jalali, Poureisa, \& Haghi, 2013, p. 21) pelanggan membeli beberapa barang tidak selalu melalui tahap keputusan pembelian. Namun beberapa pembelian sangat penting membuat pelanggan di paksa untuk mengikuti semua langkah-langkah yang ada secara teliti dan cermat.

Beberapa faktor yang mempengaruhi konsumen dalam memutuskan melakukan pembelian sebuah rumah atau tempat tinggal diantaranya adalah lokasi. Menurut Kotler (2008:51) salah satu kunci menuju sukses adalah lokasi, lokasi dimulai dengan memilih komunitas. Sedangkan menurut Fandy Tjiptono (2002:92) pemilihan tempat/lokasi fisik memerlukan pertimbangan cermat terhadap faktor-faktor berikut: Akses, Visibilitas, Lalu lintas (traffic), Ekspansi, Lingkungan, dan lain-lain.

Faktor lain yang juga dapat mempengaruhi keputusan konsumen dalam melakukan pembelian adalah faktor demografis. Demografi merupakan istilah yang berasal dari dua kata Yunani, yaitu demos yang berarti rakyat atau penduduk dan graphein yang berarti menggambar atau menulis. Oleh karena itu, demografi dapat diartikan sebagai tulisan atau gambaran tentang penduduk, terutama tentang kelahiran, perkawinan, kematian dan migrasi. Demografi meliputi studi ilmiah tentang jumlah, persebaran geografis, komposisi penduduk, serta bagaimana faktor faktor ini berubah dari waktu kewaktu. Istilah ini pertama kali dikemukakan oleh Archille Guillard pada tahun 1855 dalam karyanya yang berjudul "elements de statistique humaine, ou demographie comparree" atau elements of human statistics or comparative demography (dalam Iskandar, 1994).

Selain faktor di atas juga tak kalah pentingnya adalah faktor sarana prasarana. Menurut Departemen Permukiman dan Prasarana Wilayah (CBUM, 2002) yang mendifinisikan prasarana dan sarana sebagai suatu bangunan dasar yang sangat diperlukan untuk mendukung kehidupan manusia yang hidup bersama-sama dalam suatu ruang yang terbatas agar manusia dapat bermukim dengan nyaman dan dapat bergerak dengan mudah dalam segala waktu dan cuaca, sehingga dapat hidup dengan sehat dan dapat berinteraksi satu dengan lainnya dalam mempertahankan kehidupannya.

Dari permasalahan tersebut maka penelitian ini bertujuan untuk mengetahui bagaimanakah pengaruh dari lokasi, demografi dan sarana prasarana terhadap keputusan masyarakat untuk membeli rumah tinggal di Kota Surakarta.

\section{TINJAUAN PUSTAKA}

\section{Perilaku Konsumen}

Krisis ekonomi global telah menentukan banyak perubahan dalam perilaku baru konsumen dan telah menyebabkan sebagian konsumen untuk

mencari landmark baru. Konsumen menjadi lebih ekonomis, lebih bertanggung jawab dan lebih menuntut yang lebih banyak. Banyak penelitian tentang pasar menyadari hal ini dalam 3 tahun terakhir. (Voniea \& Filip, 2011, p. 14).

\section{Model Keputusan Pembelian Konsumen/Minat Pembelian Konsumen}

Rangsangan pemasaran terdiri dari 4Ps (product, price, place, promotion), selain itu terdapat rangsangan lain yang bertindak sebagai kekuatan utama dalam lingkungan pembeli: economic technological, political, dan cultural. Semua stimuli tersebut di kelompokkan ke dalam buyer black box dan bergantung pada pengaruh dari karakteristik pembeli. Pembeli yang datang berdasarkan respons pembeli : product choice, brand choice, dealer choice, purchase timing, dan purchace amount. (Kotler, Armstrong, Wong, \& Saunders, 2008, p. 239). 


\section{Faktor yang Mempengaruhi Perilaku Pembelian Konsumen}

Menurut (Peter \& Olson, 2010, p. 258 - 353), perilaku pembelian konsumen dipengaruhi berbagai macam faktor eksternal dan faktor internal, seperti faktor budaya, faktor sosial, faktor pribadi dan faktor psikologi.

\section{Proses Pengambilan Keputusan Pembelian}

Menurut Gilaninia (2010) dalam (Jeddi, Atefi, Jalali, Poureisa, \& Haghi, 2013, p. 21) pelanggan membeli beberapa barang tidak selalu melalui tahap keputusan pembelian. Namun beberapa pembelian sangat penting membuat pelanggan di paksa untuk mengikuti semua langkah- langkah yang ada secara teliti dan cermat. Tahap-tahapnya mencakup:

- Mengidentifikasi masalah (Identify the problem)

- Mengumpulkan data/ informasi (Data Collection)

- Menafsirkan pilihan yang ada (Assessment Options)

- Melakukan pembelian (Purchase)

- Setelah melakukan pembelian (After Purchase Behavior)

\section{Lokasi}

Menurut Swastha (2002:24) "Lokasi adalah tempat dimana suatu usaha atau aktivitas usaha dilakukan". Faktor penting dalam pengembangan suatu usaha adalah letak lokasi terhadap daerah perkotaan, cara pencapaian dan waktu tempuh lokasi ke tujuan. Faktor lokasi yang baik adalah relatif untuk setiap jenis usaha yang berbeda.

6. Demografi

Demografi merupakan istilah yang berasal dari dua kata Yunani, yaitu demos yang berarti rakyat atau penduduk dan graphein yang berarti menggambar atau menulis. Oleh karena itu, demografi dapat diartikan sebagai tulisan atau gambaran tentang penduduk, terutama tentang kelahiran, perkawinan, kematian dan migrasi. Demografi meliputi studi ilmiah tentang jumlah, persebaran geografis, komposisi penduduk, serta bagaimana faktor faktor ini berubah dari waktu kewaktu. Istilah ini pertama kali dikemukakan oleh Archille Guillard pada tahun 1855 dalam karyanya yang berjudul "elements de statistique humaine, ou demographie comparree" atau elements of human statistics or comparative demography (dalam Iskandar, 1994).

\section{Sarana Prasarana}

Menurut Kamus Besar Bahasa Indonesia (1997:880) Sarana adalah fasilitas penunjang yang berfungsi untuk penyelenggaraan dan pengembangan kehidupan ekonomi, sosial dan budaya dalam mencapai maksud dan tujuan. Prasarana lingkungan pemukiman merupakan kelengkapan dasar fisik lingkungan yang memungkinkan lingkungan pemukiman dapat berfungsi sebagaimana mestinya (Grigg,1988).

Hal senada juga dikemukakan oleh Departemen Permukiman dan

Prasarana Wilayah (CBUM, 2002) yang mendifinisikan prasarana dan sarana sebagai suatu bangunan dasar yang sangat diperlukan untuk mendukung kehidupan manusia yang hidup bersama-sama dalam suatu ruang yang terbatas agar manusia dapat bermukim dengan nyaman dan dapat bergerak dengan mudah dalam segala waktu dan cuaca, sehingga dapat hidup dengan sehat dan dapat berinteraksi satu dengan lainnya dalam mempertahankan kehidupannya.

\section{Penelitian Terdahulu}

Penelitian yang dilakukan oleh Nisa Marisa (2013) yang berjudul Analisis Faktor-Faktor Yang Mempengaruhi Keputusan Pembelian Konsumen Terhadap Kawasan Perumahan Mustika Plamongan Elok Semarang. Berdasarkan hasil analisis yang dilakukan dapat diketahui bahwa persepsi kualitas rumah, ketertarikan iklan brosur, dan word of mouth berpengaruh positif dan signifikan terhadap citra kawasan serta persepsi kualitas rumah, ketertarikan iklan brosur, word of mouth dan citra kawasan berrpengaruh positif dan signifikan terhadap keputusan pembelian perumahan Mustika Plamongan Elok. M. Erma Widiana (2009) dengan judul Analisis Faktor - Faktor Yang Mempengaruhi Keputusan Konsumen Dalam Membeli Rumah (Studi Kasus Perumahan Viharta PT.MBP - Gresik). Hasil dari penelitian analisis faktor atas 24 variabel yang mempengaruhi keputusan konsumen dalam membeli rumah di PT. MBP ternyata lebih baik diringkas menjadi tujuh faktor baru, di mana ketujuh faktor baru tersebut dapat mewakili keseluruhan data sebanyak 58,019\%. Adapun tujuh faktor inti atau baru yang merupakan hasil pengolahan analisis faktor adalah sebagai berikut: Faktor produk, faktor harga, faktor fasilitas, faktor promosi, faktor referensi, faktor discount, faktor kredit. Sedangkan Tuti Ediati (2014) dalam penelitiannya yang berjudul Analisis Faktor-Faktor Yang Mempengaruhi Pengambilan Keputusan Konsumen Dalam Pemembelian Perumahan Di Surakarta didapatkan hasil bahwa harga, lokasi, bangunan dan lingkungan berpengaruh terhadap keputusan konsumen dalam pembelian perumahan type 45/90 di kota Surakarta. 
Edy Suryawardana, Tri Endang Yani (2017) yang berjudul Analisis Faktor-Faktor Pertimbangan Konsumen Terhadap Keputusan Pembelian Produk Hunian Di Kecamatan Tembalang Kota Semarang didapatkan hasil sebagai berikut: harga, lokasi, fasilitas dan desain produk berpengaruh secara positif dan signifikan terhadap keputusan pembelian.

\section{METODOLOGI PENELITIAN}

Jenis penelitian ini merupakan penelitian survey yang dilakukan di

Kota Surakarta. Dalam penelitian ini sebagai populasinya seluruh masyarakat

kota Surakarta yang membeli rumah tinggal. Sampel yang digunakan dalam penelitian ini berjumlah 100 responden dengan pertimbangan telah memenuhi syarat yang ditetapkan. Teknik pengambilan sampel yang digunakan adalah accidental sampling yaitu siapa saja (konsumen) yang secara kebetulan bertemu dengan peneliti dapat digunakan sebagai sampel, bila dipandang orang yang kebetulan ditemui itu cocok sebagai sumber data (Sugiyono, 2001:77).

Jenis data dalam penelitian ini adalah data primer yaitu data yang diperoleh langsung dari masyarakat Kots Surakarta yaitu tentang persepsi mereka terhadap variabel Lokasi, Demografi dan Sarana Prasarana serta Keputusan Membeli. Metode pengumpulan data dalam penelitian ini berupa kuesioner.

Teknik analisis yang digunakan dalam penelitian ini adalah uji instrumen penelitian berupa uji validitas dengan metode one shot method dan uji reliabilitas diukur dengan menggunakan teknik Cronbch's Alpha. Pengujian Asumsi Klasik dan pengujian hipotesis dengan Analisis regresi linier berganda, uji t, uji $\mathrm{F}$ dan uji koefisien determinasi.

Model Persamaan regresi linier berganda, sebagai berikut :

$\mathbf{Y}=\mathbf{a}+\beta \mathbf{X}_{1}+\beta \mathbf{X}_{2}+\beta \mathbf{X}_{3}+\mathrm{e}$

Keterangan :

Y : Keputusan membeli.

$\mathrm{X} 1 \quad$ : Lokasi

$\mathrm{X}_{2}$ : Demografis

$\mathrm{X} 3$ : Sarana prasarana

B : Koefisien masing-masing variabel.

E : Error Disturbance.

a : Konstanta.

D. HASIL DAN PEMBAHASAN

1. Hasil Penelitian

a. Uji Instrumen Penelitian

Hasil uji instrumen penelitian dan linieritas dapat dilihat dalam tabel di bawah ini:

\begin{tabular}{ccclc}
\hline Pengujian & \multicolumn{1}{c}{ Uji } & \multicolumn{1}{c}{ Alat } & \multicolumn{1}{c}{ Variabel } & \multicolumn{1}{c}{ Status } \\
\hline & & & Lokasi & Valid \\
& Validitas & $\begin{array}{l}\text { One shot } \\
\text { methods }\end{array}$ & $\begin{array}{l}\text { Demografi } \\
\text { Sarana Prasarana }\end{array}$ & Valid. \\
& & & Keputusan Membeli & Valid \\
\cline { 2 - 5 } Instrumen Penelitian & & & Lokasi & Reliabel \\
& & Cronbach & Demografi & Reliabel \\
& \multirow{2}{*}{ Reliabilitas } & Alpha & Sarana Prasarana & Reliabel \\
& & & Keputusan Membeli & Reliabel \\
\hline
\end{tabular}

Sumber: Hasil olah data, 2018

b. Uji Asumsi Klasik

Berikut ini adalah hasil perhitungan masing-masing uji asumsi klasik: 
1) Uji Multikolonieritas

Tabel 2. Uji Multikolonieritas

\begin{tabular}{|l|l|l|}
\hline \multirow{2}{*}{ Model } & \multicolumn{2}{|c|}{ Collinearity Statistics } \\
\cline { 2 - 3 } & Tolerance & VIF \\
\hline Lokasi & 0,277 & 3,610 \\
\hline Demografi & 0,223 & 4,475 \\
\hline Sarana Prasarana & 0,544 & 1,837 \\
\hline
\end{tabular}

Sumber: Data primer diolah, 2018

Berdasarkan tabel diatas dapat disimpulkan bahwa variabel tersebut terbebas dari multikolonieritas karena nilai Variance Inflasion Factor (VIF) $<10$ dan nilai Tolerance $>0,10$.

2) Uji Autokorelasi

Tabel 3. Uji Autokorelasi

\begin{tabular}{|c|}
\hline Nilai Durbin-Watson \\
\hline 2,167 \\
\hline Sumber: Data primer diolah, 2018
\end{tabular}

Dari tabel di atas dapat dilihat nilai Durbin-Watson sebesar 2,167 akan dibandingkan dengan nilai tabel dengan menggunakan derajat kepercayaan 5\%, jumlah sampel 100 dan jumlah variabel bebas 3, maka di tabel Durbin-Watson akan didapat nilai dU 1.736 dan 4-dU 2.264. Nilai Durbin-Watson terletak diantara nilai dU dan 4-dU maka dapat disimpulkan tidak ada autokorelasi pada data yang di uji.

3) Uji Heterokedestisitas

Tabel 4. Uji Heterokedestisitas

\begin{tabular}{|l|l|}
\hline Variable & Sig \\
\hline Lokasi & 0,222 \\
\hline Demografi & 0,782 \\
\hline Sarana Prasarana & 0,407 \\
\hline
\end{tabular}

Sumber: Data primer diolah, 2018

Hasil uji heterokedastisitas menunjukkan nilai signifikansi lebih besar dari 0,05. Hal ini berarti model regresi yang digunakan tidak terjadi heterokedastisitas antar residual.

4) Uji Normalitas

Tabel 5. Uji Normalitas

\begin{tabular}{|l|l|}
\hline Keterangan & Unstandartized Residual \\
\hline Kolmogorov-Smirnov Z & 1,032 \\
\hline Asymp. Sig. (2-tailed) & 0,237 \\
\hline
\end{tabular}

Sumber: Data primer diolah, 2018

Berdasarkan pengujian normalitas data menggunakan uji statistik non parametrik Kolmogorov Smirnov. Hasil pengolahan data diperoleh nilai probabilitas value sebesar 1,032 sedangkan besarnya asymp.sig (2-tailed) adalah 0,237 > 0,05, maka model regresi memenuhi asumsi normalitas.

\section{Pengujian Hipotesis}

\section{a. Uji Regresi Linier Berganda}

Tabel 6. Hasil Uji Regresi

\begin{tabular}{|l|l|l|l|}
\hline \multicolumn{1}{|c|}{ Keterangan } & \multicolumn{1}{c|}{ Koefisien } & t hitung & \multicolumn{1}{c|}{ Signifikansi } \\
\hline Konstanta & 1,520 & 2,350 & 0,021 \\
\hline Lokasi & 0,227 & 4,859 & 0,000 \\
\hline Demografi & 0,264 & 4,627 & 0,000 \\
\hline Sarana Prasarana & 0,235 & 6,065 & 0,000 \\
\hline
\end{tabular}

Sumber: Data Primer diolah, 2018 
Diperoleh regresi linier berganda sebagai berikut:

$\mathrm{Y}=1,520+0,227\left(\mathrm{X}_{1}\right)+0,264\left(\mathrm{X}_{2}\right)+0,235\left(\mathrm{X}_{3}\right)+\varepsilon$

$$
\begin{array}{ll}
\beta 1, \beta 2 & =\text { Koefisien variabel X1 } \ldots . . X 3 \\
Y & =\text { Keputusan Membeli } \\
\mathrm{X} 1 & =\text { Lokasi } \\
\mathrm{X} 2 & =\text { Demografi } \\
\mathrm{X} 3 & =\text { Sarana Prasarana } \\
\varepsilon & =\text { Standar error }
\end{array}
$$

b. Uji t

Dari hasil uji regresi linier dapat disimpulkan bahwa:

1) Lokasi mempunyai nilai signifikansi $0,000<0,05$, sehingga dapat disimpulkan bahwa Lokasi berpengaruh signifikan terhadap Keputusan Membeli. (Hipotesis Terbukti).

2) Demografi mempunyai nilai signifikansi $0,000<0,05$, sehingga dapat disimpulkan bahwa Demografi berpengaruh signifikan terhadap Keputusan Membeli. (Hipotesis Terbukti).

3) Sarana Prasarana mempunyai nilai signifikansi $0,000<0,05$, sehingga dapat disimpulkan bahwa Sarana Prasarana berpengaruh signifikan terhadap Keputusan Membeli. (Hipotesis Terbukti).

\section{c. Uji F}

Tabel 7. Uji F (Anova)

\begin{tabular}{|l|l|l|l|}
\hline Keterangan & df & F hitung & Signifikansi \\
\hline Regression & 3 & 199,141 & 0,000 \\
\hline Residual & 96 & & \\
\hline
\end{tabular}

Sumber: Data diolah, 2018

Hasil uji secara serempak (Uji F) diketahui besarnya nilai $F=199,141$ signifikansi $0,000<0,05$. Sehingga dapat disimpulkan secara bersama-sama variabel bebas berpengaruh signifikan terhadap Keputusan Membeli.

\section{d. $\mathrm{Uji} \mathbf{R}^{2}$}

Tabel 8. Hasil Uji Determinasi

Model Summaryb

\begin{tabular}{|l|c|l|l|l|l|}
\hline Model & $\mathrm{R}$ & $\mathrm{R}$ Square & $\begin{array}{l}\text { Adjusted } \\
\text { R Square }\end{array}$ & $\begin{array}{l}\text { Std. Error of } \\
\text { the Es timate }\end{array}$ & $\begin{array}{c}\text { Durbin- } \\
\text { Watson }\end{array}$ \\
\hline 1 &, $928^{\mathrm{a}}$ &, 862 &, 857 &, 796 & 2,167 \\
\hline
\end{tabular}

a. Predictors: (Constant), Sarana Pras arana, Lokasi, Demografi

b. Dependent Variabl e: Keputusan

Sumber: Data diolah, 2018

Berdasarkan data tersebut diperoleh nilai koefisien determinasi $\left(\mathrm{R}^{2}\right)$ sebesar 0,857 . Artinya, pengaruh yang diberikan oleh variabel independen terhadap variabel dependen sebesar $85,7 \%$ sedangkan sisanya $14,3 \%$ dipengaruhi oleh variabel lain yang tidak termasuk dalam penelitian ini.

\section{Pembahasan}

a. Hasil pengujian hipotesis pertama (H1) menunjukkan bahwa variabel

Lokasi berpengaruh positif dan signifikan terhadap tingkat Keputusan Membeli Rumah Tinggal di Wilayah Kota Surakarta. Hasil ini menunjukkan bahwa Lokasi mempunyai pengaruh positif, artinya Lokasi memberikan dampak yang positif terhadap Keputusan Membeli Rumah Tinggal di Wilayah Kota Surakarta. Lokasi yang bebas banjir, dekat dengan pusat perbelanjaan untuk memenuhi kebutuhan serta suasana lingkungan yang tenang dan kondusif menjadi alasan yang kuat bagi masyarakat dalam memutuskan untuk membeli rumah tinggal. 
b. Hasil pengujian hipotesis kedua $\left(\mathrm{H}_{2}\right)$ menunjukkan bahwa variabel

Demografi berpengaruh positif dan signifikan terhadap tingkat Keputusan Membeli Rumah Tinggal di Wilayah Kota Surakarta. Hasil ini menunjukkan bahwa karakteristik Demografi juga sangat mempengaruhi seseorang untuk memutuskan membeli rumah tinggal, diantaranya adalah jarak rumah dengan tempat kerja, fasilitas yang tersedia serta lingkungan pendidikan dari masyarakat sekitar.

c. Hasil pengujian hipotesis ketiga (H3) menunjukkan bahwa variabel sarana prasarana berpengaruh positif dan signifikan terhadap Keputusan Membeli Rumah Tinggal di Wilayah Kota Surakarta. Hasil ini menunjukkan bahwa sarana prasarana sangat kuat dalam mempengaruhi seseorang untuk memutuskan membeli rumah tinggal, hal ini dapat dilihat dari tingkat pengaruh sarana prasarana merupakan variabel yang mempunyai pengaruh paling dominan terhadap keputusan membeli rumah tinggal di Wilayah Surakarta. Faktor keamanan, fasilitas listrik dan air serta tempat bermain bagi anak-anak menjadi pertimbangan yang kuat bagi seseorang untuk menentukan membeli rumah tinggal.

\section{KESIMPULAN DAN SARAN}

\section{Kesimpulan}

Berdasarkan hasil analisis data yang telah dilakukan mengenai pengaruh lokasi, demografi dan sarana prasarana terhadap keputusan membeli rumah tinggal maka dapat ditarik kesimpulan sebagai berikut:

a Lokasi yang bebas banjir, dekat dengan pusat perbelanjaan untuk memenuhi kebutuhan serta suasana lingkungan yang tenang dan kondusif menjadi alasan yang kuat bagi masyarakat dalam memutuskan untuk membeli rumah tinggal.

b. Karakteristik Demografi juga sangat mempengaruhi seseorang untuk memutuskan membeli rumah tinggal, diantaranya adalah jarak rumah dengan tempat kerja, fasilitas yang tersedia serta lingkungan pendidikan dari masyarakat sekitar.

c. Sarana prasarana sangat kuat dalam mempengaruhi seseorang untuk memutuskan membeli rumah tinggal, hal ini dapat dilihat dari tingkat pengaruh sarana prasarana merupakan variabel yang mempunyai pengaruh paling dominan terhadap keputusan membeli rumah tinggal di Wilayah Surakarta. Faktor keamanan, fasilitas listrik dan air serta tempat bermain bagi anak-anak menjadi pertimbangan yang kuat bagi seseorang untuk menentukan membeli rumah tinggal.

\section{Saran}

Berdasarkan hasil penelitian, maka saran yang dapat diberikan adalah sebagai berikut:

a. Bagi masyarakat yang mempunyai keinginan untuk membeli rumah tinggal, faktor-faktor yang mempengaruhi keputusan seseorang dalam memilih rumah tinggal yang terdiri dari faktor lokasi, demografi dan sarana prasarana perlu menjadi pertimbangan bagi seseorang dalam mengambil keputusan untuk membeli rumah tinggal di Wilayah Surakarta

b. Bagi pengembang perumahan maupun pribadi dalam menawarkan produknya diharapkan untuk memperhatikan faktor-faktor tersebut yang terbukti berpengaruh signifikan terhadap keputusan membeli seseorang dalam membeli rumah tinggal.

c. Bagi peneliti selanjutnya yang tertarik untuk melakukan kajian di bidang yang sama dapat menambah variabel independen, sehingga dapat ditemukan variabel baru yang akan meningkatkan keputusan seseorang untuk membeli rumah tinggal. Peneliti selanjutnya disarankan untuk menambah jumlah sampel dan lokasi penelitian sehingga penelitian dapat digeneralisasikan dengan baik.

\section{DAFTAR PUSTAKA}

Basu Swastha. 2002. Manajemen Pemasaran. Edisi Kedua. Cetakan Kedelapan. Jakarta: Penerbit Liberty.

Edy Suryawardana, Tri Endang Yani, 2017, Analisis Faktor-Faktor

Pertimbangan Konsumen Terhadap Keputusan Pembelian Produk Hunian Di Kecamatan Tembalang Kota Semarang. Jurnal Dinamika Sosial Budaya, Volume 19, Nomor 1, Juni 2017

Fandy Tjiptono, 2002, Manajemen Jasa, Penerbit Andi Yogyakarta. 
Grigg, N. 1988, Infrastructure Engineering and Management, John Wiley \& Sons

Iskandar, Jusman. 1994. Strategi Dasar Membangun Kekuatan Masyarakat. Jakarta: Rajawali.

Kotler, Philip. 2008. Manajemen Pemasaran Edisi 12 Jilid 2. Jakarta: Indeks..

Kotler, P, Armstrong, G, Wong, VWY \& Saunders, JA, 2008, Principles of marketing. 5th edn, Financial Times/Prentice Hall. .

M. Erma Widiana, 2009, Analisis Faktor - Faktor Yang Mempengaruhi

Keputusan Konsumen Dalam Membeli Rumah (Studi Kasus Perumahan

Viharta PT.MBP - Gresik), Majalah Ekonomi, Tahun XIX, No. 3 Desember 2009.

Nisa Marisa, 2013, Analisis Faktor-Faktor Yang Mempengaruhi Keputusan Pembelian Konsumen Terhadap Kawasan Perumahan Mustika Plamongan Elok Semarang. Jurnal Sains Pemasaran Indonesia, Volume XII, No. 3, Desember 2013, halaman 301 - 316

Peter, J. Paul, 2010, Consumer behavior \& marketing strategy, 9th ed. New York: McGraw-Hill/Irwin

Sugiyono. 2001. Metode Penelitian Administrasi. Bandung: CV. Alfabeta

Tuti Ediati, 2014, Analisis Faktor-Faktor Yang Mempengaruhi Pengambilan Keputusan Konsumen Dalam Pemembelian Perumahan Di Surakarta.

Widya Ganeswara, Vol. 24, No. 1, Juli-Desember 2014.

Voniea dan Filip, 2011, Analyzing the Main Changes in New Consumer Buying Behavior during Economic Crisis. International Journal of Economic Practices and Theories, 2011, vol. 1, issue 1, 14-19

Jeddi, S., Atefi, Z., Jalali, M., Poureisa, A. and Haghi, H., 2013. Consumer behavior and Consumer buying decision process. International Journal of Business and Behavioral Sciences. 3(5), 20-23

Mansoor dan Jalal, 2011, The Global Business Crisis and Consumer Behavior: Kingdom of Bahrain as a Case Study. International Journal of Business and Management. Vol. 6, No. 1; January 2011

Shah, Syed Saad Hussain., Jabran Aziz., Ahsan raza Jaffari., Sidra Waris.,

Wasiq Ejaz., Maira Fatima \& Syed Kamran Sherazi. 2012. The Impact of Brands on Consumer Purchase Intentions. Asian Journal of Business Management 4(2): 105-110, 2012 ISSN: 2041-8752. 